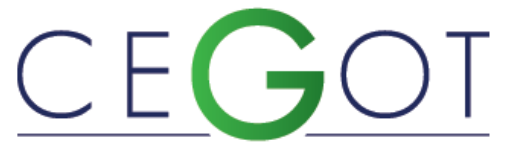

Centro de Estudos de Geografia e Ordenamento do Território
Geografia e Ordenamento do Território, Revista Eletrónica

Centro de Estudos de Geografia e Ordenamento do Território http://cegot.org

SAINTE, GUERBY

UNICAMP - Universidade Estadual de Campinas, Instituto de Geociências,

Departamento de Geografia

13083-855, Campinas, Brasil. Rua Carlos Gomes 250, Cidade Universitária. Guerby20102010@gmail.com

LÄMMLE, LUCA

UNICAMP - Universidade Estadual de Campinas, Instituto de Geociências,

Departamento de Geografia

13083-855, Campinas, Brasil

lucalammle@ige.unicamp.br

\title{
O Estado e a política da urbanização: nova perspectiva para o desenvolvimento socioeconômico da cidade de Porto Príncipe (Haiti)
}

The State and the policy of urbanization: a new perspective for the socioeconomic development of the city of Port-au-Prince (Haiti)

Referência: Sainte, Guerby; Lämmle, Luca (2019). O Estado e a política da urbanização: nova perspectiva para o desenvolvimento socioeconômico da cidade de Porto Príncipe (Haiti). Revista de Geografia e Ordenamento do Território (GOT), no 18 (Dezembro). Centro de Estudos de Geografia e Ordenamento do Território, p. 179-208, dx.doi.org/10.17127/got/2019.18.008

\section{RESUMO}

Este trabalho tem como principal objetivo analisar, primeiramente, o papel do Estado na estruturação do espaço urbano e, posteriormente, promover um debate sobre a estrutura urbana da área metropolitana de Porto Príncipe, no Haiti. O propósito foi estabelecer novas perspectivas de desenvolvimento socioeconômico, após os desastres naturais ocorridos a partir do terremoto de 2010, e da mudança na direção dos fluxos migratórios do território haitiano. Esse fenômeno decorreu, em partes, da descentralização dos serviços públicos e privados, do crescimento das favelas, da ampliação de redes urbanas no território haitiano e das dificuldades na supressão das necessidades básicas nas mais importantes regiões do país, reflexo do processo de urbanização exacerbado durante as décadas finais de século XX e do prelúdio do século XXI.

Palavras-chave: Espaço Urbano; Fluxo Migratório; Politica Urbana; Descentralização.

\section{ABSTRACT}

The objective of this work is to analyze the role of the State in the organization of urban space and subsequently to promote a debate on the urban structure of the metropolitan area of Port-au-Prince in Haiti. The purpose of establishing new prospects for socioeconomic development, following the natural disasters that occurred after the earthquake of January 12,2010 and in the change of the direction of the migratory flows of the Haitian territory. Due to the decentralization of public and private services, the expansion of urban networks under Haitian territory, and the difficulties in suppressing the basic necessities in the most important region of the country, caused in the process of urbanization exacerbated during the final decades of the twentieth century and the prelude of this century.

Keywords: Urban Space; Migratory Flows; Urban Network; Urban Policy; Decentralization. 


\section{Introdução}

O objetivo deste trabalho é discutir algumas abordagens sobre a política de urbanização do Estado e uma nova perspectiva para o desenvolvimento socioeconômico da cidade de Porto Príncipe (Haiti). Percebemos que a ocupação exagerada e inapropriada da região metropolitana de Porto Príncipe revela um grande constrangimento e impactos de ordem socioespacial, política e econômica como consequências do fenômeno da maciça urbanização mundial acelerada pela globalização. Porém, esse fenômeno da urbanização não produziu em todos os níveis as mesmas consequências em outros países da região da América Latina, cuja realidade é comparável à do Haiti em muitos aspectos (Noel, 2012). A urbanização é considerada dialeticamente como um produto da industrialização; aquela supera esta porque ainda é uma ocorrência indutora de transformações qualitativas da sociedade. E esse processo socioespacial está relacionado à dinâmica socioeconômica. Portanto, no meio do espaço urbano ou na cidade, essa proporção qualitativa do urbano está vigente nas crises da segregação de toda ordem, de habitação, das periferias e do centro, além da violência (Lefebvre, 2001).

A esse respeito, o relatório da ONU (2016) ressalta que o processo da urbanização, crescimento e desenvolvimento social é essencial para a transformação socioeconômica, no crescimento e na criação de riqueza. Esse relatório mostra que o futuro das cidades emergentes depende em grande parte das formas como o planejamento e os gerenciamentos da urbanização são feitos, de modo que esse processo de transformação possa fornecer uma configuração e impulsionar uma mudança nessa cidade. Geralmente, a urbanização baseia-se em um modelo insustentável em muitos aspectos, e até mesmo nos países mais desenvolvidos há cidades globais que estão grosseiramente despreparadas para os problemas multidimensionais relacionados à urbanização.

Do ponto de vista ambiental, o novo modelo da urbanização de baixa densidade populacional engendra a cidade, que pode ser orientada, em grande parte, pelo interesse privado, e não direcionada pelo público. Porém, no plano social, o modelo de urbanização implica múltiplas formas de desigualdade, privação e exclusão, criando as desigualdades sociais, espaciais e cidades divididas, constantemente caracterizadas por comunidades fechadas e áreas de favelas (ibidem, 2016). Compreendendo o espaço como uma totalidade, 
levando a reflexão de Lefebvre (1979), busca-se revelar como que se dá a vida na esfera concreta do acontecer cotidiano dos cidadãos haitianos na cidade de Porto Príncipe e também como que as relações entre o global e local se transformam em espaço concreto e estratégias de subversão das variadas crises econômicas e sociais que tomam naquele espaço urbano de Porto Príncipe.

Conforme reflexão de Rochefort (1998), o espaço urbano decorre de muitos fatores que tendem a fragmentar as metrópoles. E esses fatores podem ser observados nas grandes cidades dos países desenvolvidos tanto quanto nos considerados subdesenvolvidos, como no caso de Porto Príncipe, no Haiti. Segundo o autor, nos países subdesenvolvidos, a exacerbação das desigualdades sociais e a amplitude da massa das populações de baixa renda separam, de modo acentuado, as cidades entre ricos e pobres. Além disso, ao se observar os países subdesenvolvidos, as oposições são mais fortes. São os fenômenos de exclusão manifestados com mais intensidade ainda por meio de rendas modestas em espaços delimitados e afastados, tanto no centro da cidade quanto nos núcleos de polarização, os provocam, em torno de si, renovação, criação e a formação das zonas de residência de alto padrão.

Segundo análise de Santos (1980), na obra intitulada "a urbanização desigual". Particularmente, no caso do Haiti, esse processo ocorre de antemão ao planejamento urbano, levando a problemas que, ao longo dos anos, geram condições de vida deterioradas e aumentam a vulnerabilidade ambiental às catástrofes naturais no espaço urbano. Além disso, na cidade de Porto Príncipe, as condições de vida se tornam cada vez mais complicadas devido à falta de uma política pública e de um plano urbanístico para crescimento das atividades econômicas dessa cidade. Com base disso, Santos (1993) afirma que a cidade em si como materialidade e relação social se torna produtora da pobreza, tanto pela estrutura socioeconômica de que é a base como por sua organização física, que faz dos habitantes das periferias ainda mais pobres. Todavia, a pobreza não é exclusivamente o fato da estrutura socioeconômica presente, mas, também, da organização espacial.

Nesse contexto, a Periurbanização "continua a se desenvolver para além da coroa urbana propriamente dita. E o futuro da Periurbanização passa certamente pelo cuidado que se dedica às futuras operações para que elas deem uma boa imagem do espaço habitado" 
(Rochefort, 1998, p.164). De fato, a precariedade da urbanização de Porto Príncipe pode ser causada pelo fato de que as políticas públicas não incorporam as pessoas. Portanto, elas podem migrar num quadro produtivo formal na reestruturação do desenvolvimento da cidade. A falta de uma estrutura de um planejamento urbano adequado e instituições fortes levaram a um processo de gerenciamento ampliado e a uma organização adaptada a essa realidade. Nesta perspectiva, a pedra angular desse processo do planejamento urbano pode advir de uma consolidação ou reagrupamento das instituições territoriais da governança urbana da região metropolitana (Noel, 2012).

\section{Papel do Estado na urbanização: Desafios de políticas para o desenvolvimento socioeconômico}

Para Corrêa (1989), a cidade, pelo fato de ser um lugar onde habita porção gradual da população, seria uma porção da população. Este lugar pode ser usado para os investimentos de capital, definidos pelas atividades estabelecidas na cidade, particularmente no espaço urbano, o que contribui para a sua produção e é ponto de reprodução dos conflitos sociais. Desse modo, Lefebvre (2004) argumenta que a troca e o comércio são imprescindíveis para a sobrevivência da cidade e do espaço urbano, os quais suscitam o movimento e a riqueza. Portanto, a cidade como manifestação política passa a resistir com toda sua coerência e toda a sua rigidez. Tal cidade pode ser considerada, pois, um objeto espacial por ser resultado da atividade e da apropriação urbana de um lugar.

A dinâmica das atividades que se desenvolvem nas cidades são conduzidas pelas diretrizes e políticas publicas criadas pelo Estado, ou seja, o papel deste é fundamental no processo de urbanização de um país. No caso da urbanização brasileira, por exemplo, como destacado em diversos trabalhos (Guimarães, 2016; Gomes, 2015), o papel do Estado se deu, principalemente, na criação de políticas publicas habitacionais. Foi formada através de uma confrontação de opostos que interagiram para produzir um todo. De um lado, legalmente constituído, ligado à política governamental via modelo BNH (Banco Nacional de Habitação), criado em 1964, e que impulsionou, a seu modo distorcido, a resolução do problema habitacional, porque, como um banco que era, emprestava dinheiro a juros e concedia crédito a agentes privados que executavam os programas habitacionais. 
Ao longo do processo ocorrido no exemplo do Brasil, provocou-se uma série de distorções e desequilíbrios que se manifestaram empiricamente de variadas formas, pois desencadeou de uma ampla gama de demandas de exclusão e re-inclusão que concretamente cristalizamse sob as formas de desequilíbrios regionais, urbano-rurais e urbano-urbanos. Em primeiro lugar, foi fruto do desenvolvimento do capitalismo no globo e no Brasil, materializado a partir da consolidação do modelo econômico centrado na atividade industrial como vetor principal da dinâmica acumulativa. Esse modelo econômico é o principal nexo de redistribuição territorial da população, ele promoveu um desligamento e uma desterritorialização de uma população que ainda vivia circunscrita e localizada em seus lugares (Guimarães, 2016).

No caso da cidade de Porto Príncipe, este processo ocorreu de maneira distinta, pois o processo de urbanização haitiano ocorreu de maneira distinta, ou seja, o papel do Estado ocorreu de maneira diferente. Porto Príncipe passa a ser ponderada como um ponto estratégico no contexto do Haiti, de encontro e de manutenção de vida, que se estende por uma apropriação estável. Todavia, quando isso surge este contexto, não se trata como uma cidade, mas sim um agrupamento de casas, onde as pessoas dividem e se apropriam de um espaço. Essa cidade é considerada como uma representação de divisão espacial de trabalho, um lugar de troca de mercadoria e de serviços, formada por praças, monumentos históricos e palácios, além de ser usada para construção de grandes edifícios e residências de diferentes formações de classes sociais no espaço urbano. Portanto, a cidade passa a se tornar política por obter população significativa, além de ser a sede de decisão administrativa. Para Araújo (2012), a cidade política é mantida por uma relação de troca comercial porque existe um espaço que se incorpora sobre o espaço urbano. Tais situações de consolidação da cidade política entram em crise com a estabilidade da atividade comercial, que, por consequência, explode a morfologia arquitetural da cidade para ceder lugar ao encontro de pessoas com o intuito de estabelecer a atividade de troca comercial, que, porventura, contribui para a formação socioespacial do urbano.

Além da formação socioespacial da área metropolitana, esse espaço urbano sofre concomitantemente algumas fragmentações e articulações onde cada uma das partes estabelece relações sociais muito variáveis com as demais. Essas relações espaciais na sociedade capitalista implicam os investimentos de capital, circulação de decisões, mais- 
valia, juros, salários, rendas e envolvem a prática da ideologia e do poder. Tais relações espaciais são sociais e são os elementos fundamentais para a sociedade de classes (Corrêa, 1989).

Portanto, o Estado Capitalista é considerado como uma relação social que tem como principal objetivo a condensação de uma série de articulações de forças sociais. Assim, essas articulações são predominantes segundo uma série complexa de fatores estruturais e conjunturais, porque esse método interpõe-se às outras articulações atuais de igual forma à construção social. Essa articulação, ou a política de dominação, confere ao Estado a sua forma de matriz organizacional. Nesse sentido, a articulação dominante nas formações sociais capitalistas é representada por meio das relações sociais de produções e sua lógica que se aprofunda desigualmente em toda a camada social, motivado ainda pela lógica do capital. Tal raciocínio consiste numa relação de exploração, enquanto extração de mais-valia através de uma propriedade não socializada, dos meios do uso da força de trabalho apropriado no mercado e de reprodução (Santos, 1982), movimentado pelo espaço urbano.

Na compreensão do Corrêa (1989), o espaço urbano pode ser usado como uma desintegração na cidade capitalista e um reflexo social. É, por assim dizer, fortemente desigual social e economicamente, faz parte da essência própria do espaço urbano e da sociedade capitalista. Esse reflexo social da área urbana contribui para a dinamização da sociedade, que dispõe de uma mutabilidade muito complexa, com o ritmo e a natureza diferenciada que se condicionam através do papel das formas de interações espaciais, dos trabalhos fixados pela população. E tais fatores são evidenciados nas condições de investimentos para o crescimento e nas relações de produção.

Recentemente, constata-se que o espaço urbano depende majoritariamente das organizações espaciais de produção para cada contexto nacional: leis, normas de construção, sinalizações, práticas sociais, essencialmente um contexto em que os regulamentos urbanos estão ausentes e não há planejamento. Essa estrutura prática do espaço se constrói através das relações sociais que se opõem às estratégias que envolvem o espaço urbano. As práticas sociais são geradas por modelos ativos, estruturais e culturais que podem conduzir à definição de espaços versus bairros que não são comuns e que permanecem fora do familiar (Panerai et al., 1999). Podemos destacar, então, que a complexidade da evolução econômica e social tem implicação direta sobre o 
desenvolvimento da política da urbanização por falta de perspectiva do Estado no investimento e nas reconfigurações do espaço urbano dessa cidade.

Para Santos (2002), o Estado é detentor de poderes, na medida em que os seus administradores públicos, na satisfação de suas atribuições, são conscienciosos do desenvolvimento e do crescimento da grande cidade através de sua representação políticoadministrativa. Sendo assim, o Estado cumpre um papel significante para escolher dentre múltiplas possibilidades ao analisar as estratégias eficientes por meio das qualidades do espaço, como: processo, estrutura, forma e função, que são inseparáveis dentre si. Desse modo, Schmidt (1983) afirma que o Estado pode ser visto como grupo complexo de instituições específicas dentro de uma sociedade. Essa relação pode presumir a existência de forças sociais, pelas quais o Estado pode se considerar como uma condensação. Além disso, ele estabelece uma relação entre as políticas públicas e a população mediante a legitimidade que concede ao Estado. Dá-lhe a autoridade para ordenar e controlar a produção baseada num sistema econômico, na lógica de promover o crescimento econômico, e detém um mandato para estabelecer um planejamento voltado para criar e manter as condições de acumulação das riquezas e dos bens.

Nesse contexto, Soja (1993) considera a urbanização como grande aceleração do afastamento espaço-tempo. De fato, a particularidade do urbano é determinada não como uma realidade distinguida, mas pelas suas próprias regras de formação e de transformação socioespacial exclusivamente pelo reflexo e pela imposição da ordem social. Em virtude disso, o urbano ou o espaço podem ser considerados como uma parte incorporada e particularizada de uma generalização contextual mais imprescindível sobre a espacialidade da vida social. No contexto de espacialidade social, o espaço urbano possuiu a capacidade de ocorrer por um conjunto de relação de dominação, que se dirige pela diferenciação regional, pelo regionalismo, pela territorialidade e pelo desenvolvimento desigual, além das práticas nas diversas formas de escalas. Desse modo, Clos (2014) ressalta que o processo de urbanização não é considerado como uma organização simples do solo. Contudo, é constituído como uma transformação da mentalidade política, na qualidade e na capacidade do entendimento dos cidadãos, na adaptação, na aceitação das novas regras estabelecidas na convivência social para os que habitam a cidade. 
Segundo análise de Schmidt (1983), as relações de poder dependem especificamente da presença e da comunidade do processo de acumulação de capital. Porém, o Estado tem por obrigação, no contexto do capitalismo, favorecer o grau de desenvolvimento que está ocorrendo por meio de alocação e da produção. Por meio de alocação, o Estado desenvolve condições para a acumulação de modo autoritário, encarregando um caráter regulador a fim de colocar em vigor certa ordem no campo das atividades sociais, econômicas, políticas e ambientais. Além disso, o Estado possui poder de criar leis, regimentos, normas, ou seja, um sistema de ações de cunho jurídico-político capaz de influenciar (como de fato influencia) no modo de produção. O segundo mecanismo envolve várias causas, que podem ser essenciais para os insumos físicos de produção, geralmente necessários à infraestrutura para a expansão industrial. Perante isso, o Estado tem possibilidades de intervir para impedir ou expelir as ameaças sensíveis à acumulação.

Na análise feita por Lefebvre (2004), a cidade estabelece uma mediação espaço/tempo entre o nível inferior e superior. Assim, no nível superior, ela funciona em uma escala muito abrangente e apresenta o Estado e o poder econômico como atores privilegiados. Lefebvre estabelece-se na morfologia de prática-sensível da cidade por meio de diferentes formas, órgãos estatais, bancos e sede de empresas, entre outros. O raciocínio do autor se manifesta em uma ordem de consonância com as classes dominantes e coloca em prática as estratégias que instituem imposição e controle sobre as cidades. Sendo assim, essas estratégias adquirem a configuração de subsistemas do espaço urbano, tais como a vigilância e a circulação de informação, dentre outras; em suma, identificam a busca por um sistema integral. No entanto, o nível privado ou inferior representa a ação primordial, concebendo o ponto de chegada de ordens e o ponto de partida de informações. Esse nível é o que articula a vida cotidiana atual, controla o consumo em totalidade na lógica do Estado capitalista.

Nessa mesma lógica, o Estado capitalista exerce duas funções fundamentais. De um lado, a exterioridade, que representa a condição de inerência que permite o Estado fazer parte de processo de acumulação capitalista. Por outro lado, a superordinação do Estado, que permite cumprir a exigência de subordinação determinada pelo processo de acumulação e as relações sociais que ele produz no estabelecimento dos limites organizacionais diferentes na sua atuação (Santos,1982). Essa função que o Estado capitalista detém passa a ser 
promovida ou ocorrida na transformação socioespacial do espaço urbano e na imposição da ordem social. Em relação disso, Corrêa (1989) aponta que a produção do espaço urbano na sociedade capitalista e a complexidade de atividade dos agentes sociais permitem estabelecer algumas práticas que conduzem a um processo de reestruturação socioespacial que se faz via assimilação de atuais áreas ao espaço urbano e degradação de algumas outras. Também, decorrem da realocação diferenciada da infraestrutura, da densificação do uso do solo, da renovação urbana, da mudança do conteúdo social, de maneira coercitiva ou não, além de medidas econômicas e políticas determinadas nas áreas da cidade.

Nessa percepção, às cidades, por meio da sua função na urbanização, atribuem-se alguns tipos característicos por certos papéis econômicos mais ou menos influenciados pela história. De fato, isso passa a desconhecer gravemente a realidade geográfica ou negligenciar a verdadeira personalidade peculiar de cada cidade (Rochefort, 1998). Como a cidade se transforma gradativamente em um espaço que se constitui para acolher as grandes firmas, isso diminui os recursos públicos disponíveis à população, agravando a crise social. Na dinâmica de transformação da economia urbana, os territórios passam a ser considerados como formas, enquanto o território usado é objeto e ações, espaço habitado e regido pela fluidez. É marcado pelo serviço da competitividade, que atualmente favorece as relações econômicas a serem movimentadas pela cidade, de modo a reconfigurar o espaço urbano pela circulação das práticas comerciais (Santos; Souza, 1996; Santos, 2008).

Nesta perspectiva, Santos (2004) ressalta que a sociedade pode caminhar por um processo de transformação social, em que políticas, relações sociais e economia também se modificam, em ritmos e proporções variadas. O mesmo fenômeno pode acontecer em relação à paisagem e ao espaço, que se metamorfoseiam para se harmonizar às novas necessidades da sociedade. Na análise de Corrêa (1989), o Estado tem um papel fundamental na organização espacial de uma cidade, mesmo que a representação seja muito complexa e diversificada tanto no tempo quanto no espaço, exprimindo a dinâmica da sociedade que the concede ou representa. Porém, o Estado funciona como grande industrial, consumidor do espaço e promotor imobiliário, proprietário fundiário de localizações específicas, e serve como um agente regulador do uso do solo. Portanto, as diferentes formas de usos de território determinam como o centro de cada uma das cidades (área local de concentração de atividades comerciais, área industrial, áreas residenciais 
usadas pelo conteúdo social, de gestão, de serviços e de lazer) implicará, de maneira independente, uma expansão do espaço urbano.

Segundo o autor, o Estado possui um conjunto de mecanismos para implementar na relação do espaço urbano. Sua representação é marcada pelas divergências de interesses entre diversos membros da sociedade de classes, comunitárias, bem como na associação entre eles, e tem preocupação na defesa dos interesses das classes dominantes quando estão no poder. Além disso, esta atuação se faz visando a estabelecer condições de efetivação e reprodução da sociedade capitalista, de modo que essas condições proporcionem o processo de concentração de suas frações da sociedade e da reprodução das classes sociais (Corrêa, 1989).

Para Schmidt (1983), a situação da política latino-americana contemporânea, geralmente desagregadora, foi prejudicada pelo modo de funcionamento do Estado, estruturado pelas elites conservadoras. Esse plano econômico coloca em prática muitas políticas que foram ampliadas na base do sistema de acumulação de capital. Neste contexto, a participação do capital estrangeiro possui um papel indispensável nesta ação. Porém, a produtividade nacional deveria ser estendida para atender uma demanda muita ampla ao incorporar um sistema mais recente no estágio de desenvolvimento das forças produtivas a fim de principiar um novo ciclo econômico. Por isso, o papel do Estado é muito relevante para o fornecimento das bases jurídico-legais e infraestruturas para dar suporte ao capital estrangeiro, representado por grandes firmas multinacionais.

Segundo Schmidt (1983), a política urbana é determinada pela tentativa sistemática de enfrentar as externalidades ocasionadas pelo desenvolvimento de uma economia do mercado. Nesta perspectiva, a política urbana estabelecida pelas políticas públicas pode projetar um contexto de fortes pressões diretas sobre a capacidade de reagir do Estado, mas essas políticas têm de ser vistas como motivações que predizem as modificações da essência particular do Estado. 


\section{Urbanização do território haitiano: concentração populacional em Porto Príncipe}

De acordo com Clos (2014), o processo da urbanização é um elemento determinante para o desenvolvimento de um país. Ela apresenta uma grande qualidade no crescimento dos valores econômicos numa sociedade e facilita um acréscimo da produtividade local, regional ou nacional, permitindo que esta cidade ou país entre no processo de competitividade. Ora, no caso do Haiti, isso não é um fato. Pelo contrário, a urbanização é acompanhada pelo crescimento da pobreza, da marginalização e da exclusão social e espacial. Na compreensão de Santos (2002), quando a população total passa a aumentar, a população urbana e a população industrial não são efeitos de execução da ação do movimento próprio das frações das localidades nas diferentes regiões e espaços do território. Todavia, esse movimento global é capaz de ocorrer em um conjunto de forças, de forma mais geral, e são responsáveis pela distribuição geográfica das múltiplas variáveis sobre o conjunto.

A economia de aglomeração, ou de grande escala, leva à redução dos preços e dos custos de operação da ação comercial; consequentemente reduziu a contiguidade e permite, portanto, um forte crescimento da produtividade econômica de dada cidade. Em decorrência dessa análise, quando uma cidade passa a ser urbanizada, a sua atividade econômica amplia-se na medida em que há aglomeração de pessoas não somente nas áreas mais nobres das cidades, mas também nas periferias. Esses tipos de atividades comerciais praticadas nas periferias funcionam de forma nem sempre irregulares, mas tais atividades permitem aos cidadãos da periferia uma maneira alternativa de gerarem renda, contribuindo para a movimentação e para o crescimento socioeconômico da cidade (Clos, 2014).

Desse modo, Lefebvre (2001) enfatiza que a cidade possuiu relações com a sociedade na sua totalidade, com seu funcionamento e com sua composição, com seus diferentes componentes, como campo e agricultura, poder político, o Estado, dentre outros. Portanto, a cidade apresenta uma modificação quando a sociedade a transforma na sua totalidade. Entretanto, essas transformações da cidade não apresentam as consequências passivas da globalidade, de suas alterações na sociedade ou na estrutura urbana. Em virtude disso, a cidade pertence também às vinculações do imediato, dos grupos e das relações diretas 
entre as pessoas que compõem a sociedade, tais como grandes corporações e famílias. Essa cidade não pode ser sintetizada à estrutura organizacional dessas relações diretas e instantâneas, nem suas transmutações se resumem às mudanças feitas no meio da sociedade.

Na análise feita por Clos (2014), o processo da urbanização resulta não somente de um meio físico, ou de uma mudança social, mas sim de um processo que é geralmente cultural e incompreensível. Isso depende principalmente das normas estabelecidas e das estratégias do governo para construir as casas para as pessoas empobrecidas numa determinada região em que a maioria das pessoas preferem não permanecer. Porém, essa acumulação de habitação, sob hipótese alguma, forma uma cidade.

Para Santos (1982), essa inquisição da urbanização é compreendida como uma dificuldade social provocada pelo crescimento rápido e anárquico das cidades nas sociedades capitalistas. Esse problema é provocado em decorrência do déficit dos transportes públicos, dos problemas habitacionais, pela questão do saneamento e pela poluição, dentre outros, e são geralmente funções integrantes do espaço urbano e das cidades. Isto se refere a um conjunto de dificuldades sociais particulares promovidos fora do âmbito de trabalho e da produção, e que não é ao capital, mas à sociedade na sua totalidade e, portanto, ao Estado que cabe resolver. É por meio dessa percepção que a sociedade capitalista se atribui a função urbana e enfrenta um conjunto de ações e medidas que se chama de política urbana, um processo pelo qual se integram a política de habitação, a de saneamento, a de transportes e a de antipoluição do espaço urbano.

Refere-se à ideia de Corrêa (1997), espaço urbano é considerada como a consequência da conduta, que muitas vezes conflitantes, de diferentes agentes sociais. Entre os atores está o Poder Municipal, pois é a ele que cabe a função de ordenar e planejar o crescimento das cidades. Se o espaço urbano é um condicionante social, este é também condicionado socialmente e, seja pela ação ou omissão, é principalmente por meio do Estado que se dá este condicionamento. Se for observar na estrutura espacial de Porto Príncipe, a organização urbana é desordenada, na medida em que a cidade cresce de forma não planificada; a ausência do Poder Público local acaba por facilitar bairros irregulares por falta de serviços e equipamentos, situações comuns de muitos bidonvilles em Porto Príncipe 
onde o abastecimento de água saneamento básico, rede de esgoto, espaço verde, tratamento de água para o consumo da população.

De acordo com relatório da ONU (2016), em 1990, o mundo passou por um forte aumento de seus cidadãos nas áreas urbanas. Esta tendência não é nova, mas foi marcada por um aumento de 57 milhões de pessoas entre 1990-2000 e 77 milhões entre 2010-2015. Em 1990, esse valor correspondia a cerca de $43 \%$ (2,3 bilhões) da população mundial vivendo em áreas urbanas enquanto; em 2015, cresceu para 54\% (4 bilhões).

No caso do Haiti, Keane (2013) ressalta que, na década de 1950, o crescimento da população urbana haitiana já tinha uma previsão de aumento. Ao se observar em relação aos países do Caribe, a urbanização do Haiti representa um nível muito inferior. Em 2010, o país tinha $47 \%$ da população vivendo nas áreas urbanas, um valor muito reduzido se comparado com outros países na região, como Cuba, com $75 \%$ da população em áreas urbanas, 52\% na Jamaica, e a República Dominicana com 66\%, além dos impressionantes 98\% da população de Porto Rico concentrada nas áreas urbanas. Devido à fragilidade da produção rural e agrícola, à falta de condições para melhoria de condições de vida socioeconomicamente, ao desemprego e à ausência da infraestrutura básica nas diversas regiões do Haiti, houve um crescimento excessivo da população na área urbana. Nesse caso, - Estado deve tomar as medidas necessárias para reduzir esse movimento migratório pelo processo de desconcentração e da descentralização industrial. A tabela 1 mostra a população urbana, rural, a superfície e a densidade demográfica de cada departamento, referentes ao ano de 2014 e disponibilizadas em 2015 pelo Institut Haïtien de Statistique et d'Informatique (IHSI).

Observamos que a área metropolitana tem uma população urbana que continua a crescer mais na parte Oeste do país, sendo que as populações que têm os maiores bens materiais, grandes propriedades e riquezas estabelecem-se na parte superior de Porto Príncipe, como Pétion-Ville, Fermathe, Thomassin. Por sua vez, as áreas mais empobrecidas ficam na parte da planície (área mais rebaixada), como Liberdade, Cité L'éternel, Bréa e Sanatorium. Porém, a cidade de Porto Príncipe põe em ordem três grandes áreas urbanas, tais como Pétion-Ville, Delmas, Fermathe, com as particularidades culturais, geográficas e socioeconômicas (WFP, 2016). 
Tabela 1 - População por Departamento no Haiti e número Residente na área urbana e rural referentes ao ano de 2014.

\begin{tabular}{cccccc}
\hline Departamento & Total & Área Urbana & Área Rural & $\begin{array}{c}\text { Superfície em } \\
\mathbf{k m}^{\mathbf{2}}\end{array}$ & $\begin{array}{c}\text { Densidade } \\
\text { Demográfica } \\
\text { (hab./km } \mathbf{~})\end{array}$ \\
\hline $\begin{array}{c}\text { Oeste } \\
\text { Artibonite }\end{array}$ & 4.029 .705 & 3.397 .404 & 632.301 & $4.982,60$ & 808,76 \\
Norte & 1.067 .177 & 538.875 & 528.302 & $2.886,90$ & 353,50 \\
Sul & 774.976 & 176.485 & 598.491 & $2.653,60$ & 292,05 \\
Centro & 746.236 & 151.488 & 594.748 & $3.487,40$ & 213,98 \\
Noroeste & 728.807 & 203.568 & 525.239 & $2.102,90$ & 346,57 \\
Sudeste & 632.601 & 96.454 & 536.147 & $2.034,10$ & 296,25 \\
Grand-Anse & 468.301 & 110.488 & 357.813 & $1.911,90$ & 244,94 \\
Nordeste & 393.967 & 190.926 & 203.041 & $1.622,90$ & 242,75 \\
Nippes & 342.525 & 62.211 & 280.314 & $1.267,80$ & 270,17 \\
\hline Total & $\mathbf{1 0 . 9 1 1 . 8 1 9}$ & $\mathbf{5 . 6 6 7 . 6 8 6}$ & $\mathbf{5 . 2 4 4 . 1 3 3}$ & $\mathbf{2 7 . 0 6 5 , 3 0}$ & $\mathbf{4 0 3 , 1 7}$ \\
\hline
\end{tabular}

Fonte: Tabela elaborada pelo autor a partir dos dados adaptados pelo Institut Haïtien de Statistique et d'Informatique (IHSI) (2015).

Segundo Lefebvre (2001), a realidade urbana e a cidade estão sujeitas ao valor de uso. Entretanto, a globalização da mercadoria pela industrialização e do valor de troca encaminha a direção de destruição, ao subordiná-las a si, cabendo dizer que a cidade e a realidade urbana são refúgios do valor de uso, origens de uma potencial preeminência e de uma relevância do uso, o que intervém na prática da urbanização dessa cidade. No mesmo raciocínio de Lefebvre (1991), há uma inquisição essencial na análise da noção de cidade, que é a ligação entre o Produto e a Obra. Essa correlação é uma interpretação da dialética de valor de troca/valor de uso e se confirma ao longo das organizações das cidades. Provém da reflexão de que a cidade é uma construção de obra, quer dizer, o local privilegiado, de transformação e combinação de relações sociais e de estabelecimento de centralidades. 0 autor faz uma crítica ao sistema de urbanização contemporânea através do modo de produção da sociedade capitalista. Sendo assim, a cidade ocupa uma função de projeção de uma sociedade sobre um local e permite se tornar cada vez mais um valor de troca, um produto a ser consumido.

Ainda de acordo com Santos (2002), quando a sociedade se transforma e passa a remover também as quantidades e qualidades de suas funções, essas funções se constituem onde as condições de instalações se colocam à disposição como melhores. De fato, essas áreas 
geográficas de execução concreta da totalidade social apresentam um papel apenas funcional. Entretanto, as alterações/transformações são estruturais e globais, envolve a sociedade, isto é, a formação socioeconômica.

Em decorrência disso, as populações nas áreas urbanas da região metropolitana de Porto Príncipe aumentam devido ao processo de êxodo rural nas diversas regiões do país (Keane, 2013). Assim, a população rural do país sofre um desemprego muito grande por conta da redução da produtividade agrícola, da falta de recursos financeiros para sustentar a produção da agricultura, além da escassez de mão de obra. Ressalta-se, também, a carência de investimentos do Estado no desenvolvimento da agricultura mecanizada e da infraestrutura, elementos de base no processo do desenvolvimento e facilitadores do crescimento econômico. Além disso, há a falta de atividades geradoras de renda e de riquezas nas diversas áreas regionais, rurais e municipais do país, perante a centralização e a concentração das principais atividades mais sensíveis ligadas ao setor terciário que estão na cidade metropolitana de Porto Príncipe (Emmanuel et al., 2000).

Sendo assim, em 1982, a população metropolitana de Porto Príncipe era de 720.000 habitantes. Em 32 anos, a população nacional passou de uma taxa de crescimento de menos de $5 \%$ para $14 \%$. Porém, no início do ano de 1980, a região metropolitana do Porto Príncipe abrangia dois terços das empresas do país, e cerca de $90 \%$ delas foram empregadas na indústria de manufatura. Nesse contexto, foi possível que a população de Porto Príncipe aumentasse de maneira exacerbada. No ano de 1989, por exemplo, a população residente em Porto Príncipe era de 940.000 habitantes. Vinte anos mais tarde, a região metropolitana era mais do que 1.5 milhão de habitantes; e entre essa data e 2014, a população da capital haitiana quase duplicou, sendo estimada em 2,7 milhões de habitantes em decorrência do terremoto (Keane, 2013).

Devido ao crescimento da população na área metropolitana de Porto Príncipe, o Estado pode estabelecer e facilitar uma maior integração dos habitantes nas políticas públicas a fim de promover uma maior melhor contribuição no desenvolvimento sustentável, socioeconômico, político e imobiliário do país. Nesse sentido, as grandes cidades possuem as condições gerais de habitação da população, de modo que ela tenha acesso e acessibilidade aos serviços básicos, exercendo uma influência positiva sobre a produtividade e a expectativa de vida da população e contribuindo para o envolvimento da sociedade no 
mercado do trabalho. Nesse contexto, este é um fato importante na construção de uma sociedade e faz parte do movimento da globalização de mercados da sociedade moderna (Emmanuel et al., 2000).

Além disso, em 1990, a população urbana do Haiti tinha na época $29 \%$ da população nas áreas urbanas. Enquanto, que no ano de 2015, a população residente na área urbana, quase duplicou para $52 \%$ e com estimativa de atingir $76 \%$ em 2050 . Por isso, poderia haver uma mudança nas taxas da população urbana haitiana devido ao fato de 2.6 milhões de pessoas que se instalam na área metropolitana do Porto Príncipe, que representarem $1 / 4 \mathrm{da}$ população haitiana (IHSI 2015; WFP, 2016).

No ano de 2015 , a população residente na área urbana quase duplicou, para $52 \%$, com estimativa de atingir 76\% em 2050. Por isso, poderia haver uma mudança nas taxas da população urbana haitiana devido ao fato de 2,6 milhões de pessoas se instalaram na área metropolitana do Porto Príncipe, o que representa 1/4 da população haitiana (IHSI 2015; WFP, 2016). Em 25 anos, o Haiti passou de um país rural a um país urbano; saiu de $20 \%$ de população urbana para $52 \%$ dos seus habitantes morando em cidades, sendo que cerca de um terço da população está concentrada no departamento do Oeste do território. Sendo assim, esse Departamento envolve todas as decisões institucionais e estatais do país graças à concentração dos serviços públicos nacionais. De tal maneira, o país possui um quadro institucional e jurídico e a autoridade para implementar e estabelecer uma nova estratégia para criar o espaço urbano renovado com novo plano, estruturas e novas regras fornecidas pelo Estado (Clos, 2014).

Em relação a isso, grande parte da população haitiana passa a viver na região metropolitana de Porto Príncipe, cerca de $30 \%$, devido ao forte investimento ao trabalho formal do país (90\% do investimento). Além disso, é concentrada a maioria dos atributos econômicos, políticos e socioculturais na cidade do Porto Príncipe, sendo uma opção para a economia nacional por se tratar de um dos polos mais atrativos à população haitiana. De fato, com a falta de empregos nas outras regiões do país, a densidade de infraestrutura, a habitação, a terra e os serviços públicos, que já eram geralmente insustentáveis antes da tragédia de 12 de janeiro de 2010, podem ficar mais graves com o crescimento urbano esperado para os próximos anos, a menos que sejam executadas medidas mitigadoras e um novo plano pelo planejamento urbano seja posto em prática. Do contrário, isso faz com que essa cidade 
continue a vivenciar um aumento nas taxas de urbanização, com a previsão de poder ter mais de quatro milhões de pessoas na região metropolitana nos próximos dez anos (UNHatitat, 2009; Keane, 2013).

Além disso, em 1990, a população urbana do Haiti correspondia a $29 \%$ do total. Nesse contexto, 75.000 migrantes internos se estabeleceram na cidade metropolitana nos últimos 20 anos. Diante disso, o crescimento dos cidadãos na capital era de 40.000 por ano, e atualmente aumentou para 115.000 por ano (World Bank, 2006; Keane, 2013).

Cano (2011) enfatiza que a internalização do desenvolvimento pode ser analisada de fato como uma ação mais geral. A economia capitalista implica questões migratórias e interfere na incrementação capitalista no processo de produção no campo, sendo maior que a própria dinâmica da ampliação e modificação dos serviços nos centros urbanos deste país. Além disso, há a crítica da política de se afastar do centro da interiorização sem se superar o risco das falsas soluções no processo de descentralização. Isso implica que o Estado deva usar outra estratégia para repensar as políticas da região metropolitana e sua adequação, adotando uma nova forma para redesenhar a política de localização individual e para repensar a dinâmica do fenômeno da urbanização.

\section{O cenário atual da organização socioespacial da cidade de Porto Príncipe}

O sistema urbano nacional é fortemente desequilibrado e dominado pela área metropolitana de Porto Príncipe, onde habitam em torno de $65 \%$ da população urbana do Haiti, com mais de 3,4 milhões de habitantes (CIAT, 2014). A Região Metropolitana de Porto Príncipe é formada por cinco municípios: Porto Príncipe, Delmas, Pétion-Ville, Carrefour e Kenscoff.

Na questão da gestão dos serviços urbanos depois do terremoto de 12 de janeiro de 2010, Lombart et al. (2012) concordam com a ideia de Desse et al. (2012) de que, após a catástrofe natural, as fraquezas das organizações da gestão urbana de serviços urbanos e o controle na gestão estatal aumentaram devido à falta de iniciativa do governo haitiano. Porém, essa tragédia resultou também na mudança do sentido dos fluxos migratórios, ou seja, passou do 
campo para a capital. Com a volta imprevista e incontrolável das pessoas, aumentaram as dificuldades de gerenciamento do espaço urbano para os administradores públicos locais na distribuição da assistência social na cidade de Porto Príncipe. Em referência à análise do espaço urbano, a cidade, para Lefebvre (2004), é considerada como uma transição entre a ordem próxima e a ordem distante, ou melhor, entre o campo que a envolve e a sociedade em sua totalidade. Nesse sentido, se a catástrofe estabelece no espaço urbano ou na cidade, quer dizer que ela também pode se evidenciar no campo e na sociedade em geral, porém em impetuosidade e movimentos distintos.

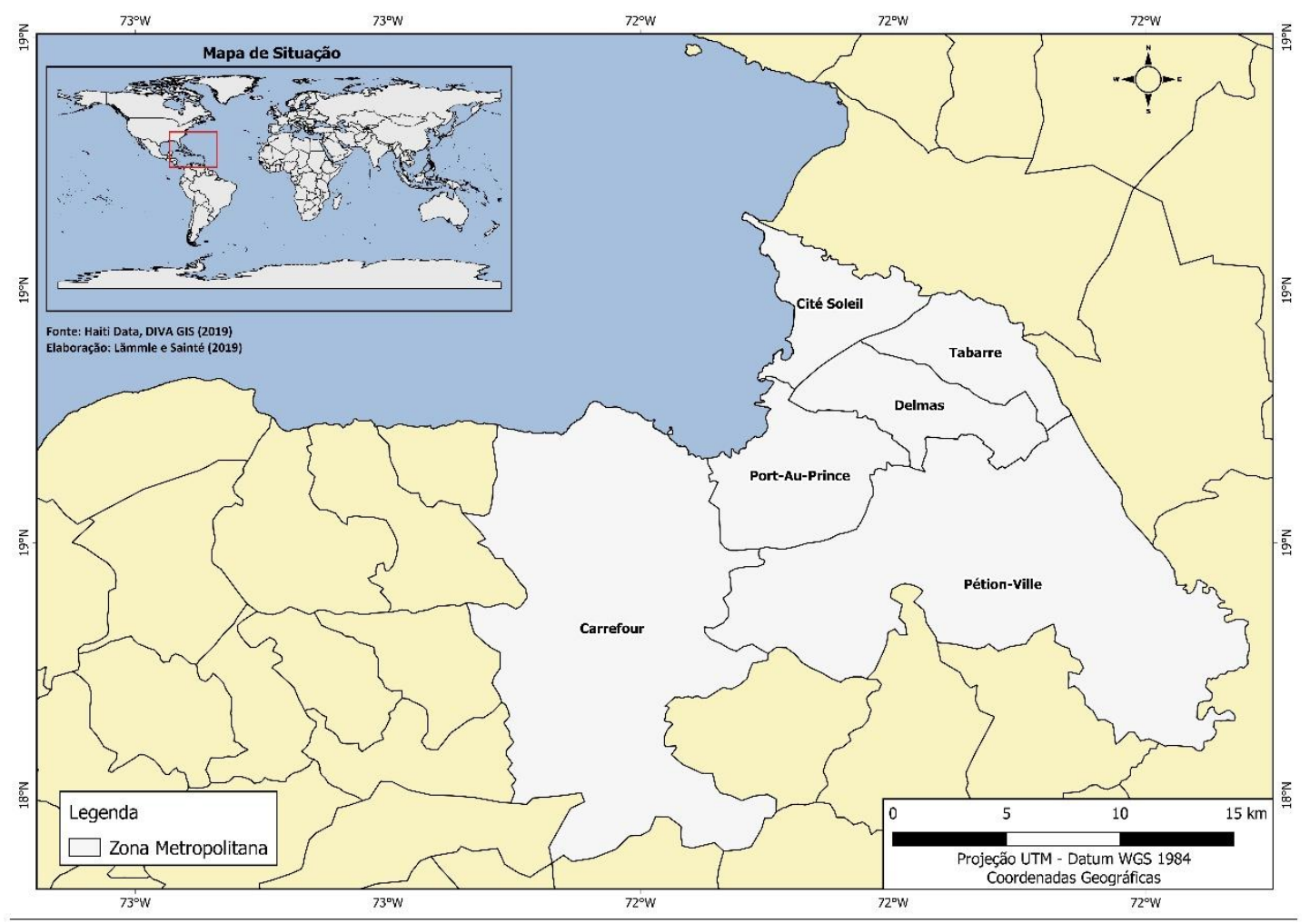

Fig. 1 - Localização da Região metropolitana de Porto Príncipe.

Fonte: USAID (2009).

Para Santos (2002), os movimentos da sociedade concedem contribuições para recentes funções das formas geográficas, oferecem nova forma; estrutura do espaço desenvolve situações de equilíbrio e novos objetos de partida para uma nova transformação socioespacial e ambiental. Para o autor, é de fundamental importância possuir uma vida que seja sempre renovada pelo social. As formas reconduzidas, assim, formas-conteúdo, possuem a capacidade de contribuir em uma dialética junto com a própria sociedade, que 
passa a se envolver no sistema de desenvolvimento da sociedade. Nesse sentido, esse fenômeno não fica restrito apenas aos movimentos migratórios tradicionais das pequenas cidades e lugares para os centros urbanos, mas também, como verificado no Haiti, brevemente após a ocorrência de terremoto de 2010, fizeram seus caminhos inversos: das grandes áreas urbanas para as pequenas. Tal fenômeno é ilustrado pela figura 2.

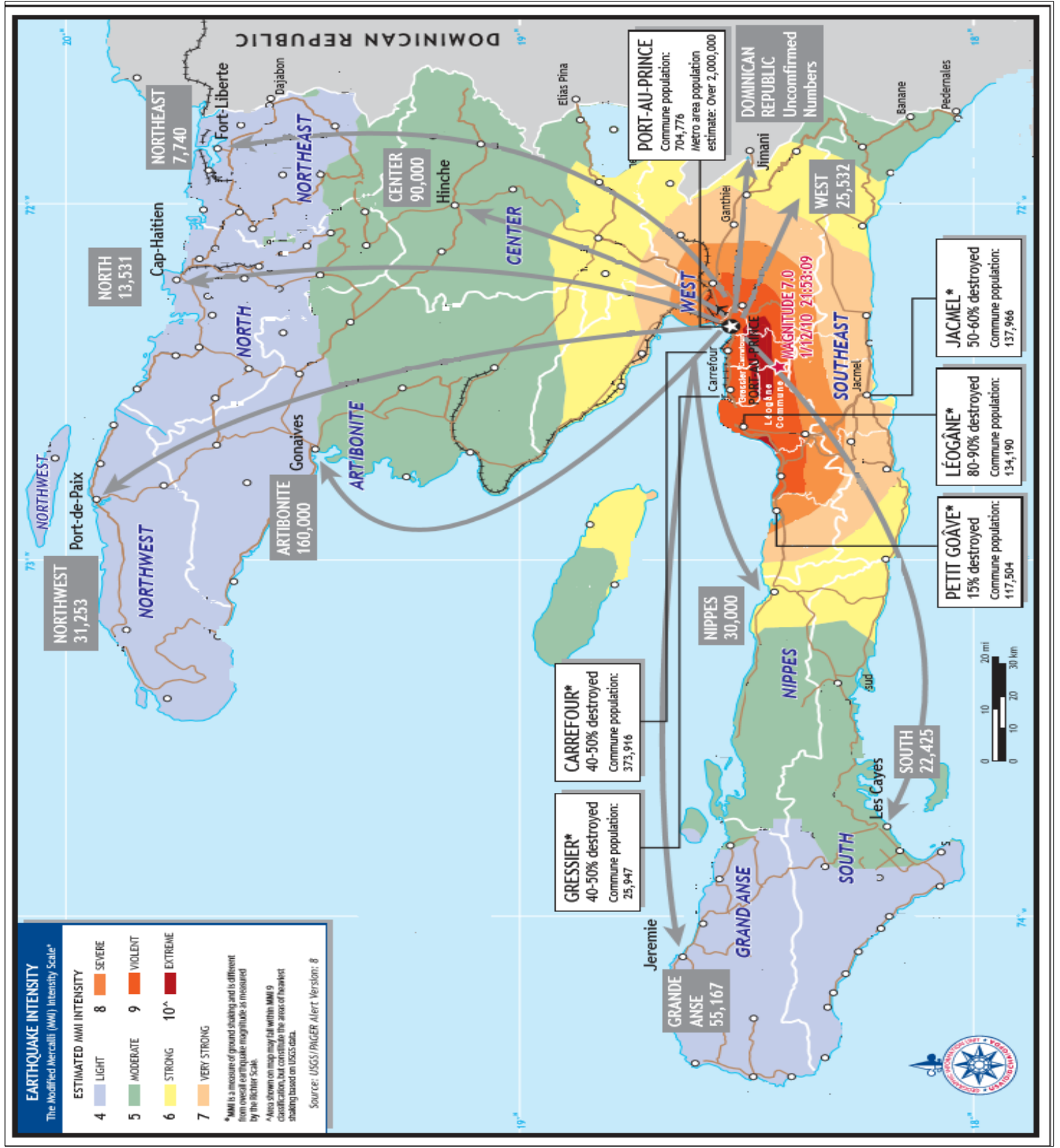

Fig. 2 - Terremoto de 12 de janeiro de 2010 - deslocamentos da população haitiana para suas cidades.

Fonte: USAID (2010). 
O espaço urbano da capital Porto Príncipe se transformou devido à reestruturação da infraestrutura do país. No entanto, essa cidade permanece como sede das funções administrativas e políticas, e continua como o principal centro das atividades comerciais do Haiti. Porém, a capital enfrenta vários problemas que às vezes prejudicam as atividades de circulação do município. Em decorrência dessas dificuldades, houve transferências de vários serviços públicos, o que permitiu um crescimento da construção das sedes de empresas privadas e de construção de fábricas ao longo das rodovias da região metropolitana de Porto Príncipe (Godard, 1988).

$\mathrm{Na}$ análise feita por Lombart e Rondon et al. (2012), grandes parcelas das cidades do Haiti antes da tragédia de 12 de janeiro de 2010 eram construídas sem um real controle, com falta de estrutura urbana e sem centralização da informação. Ou seja, com a falta de fiscalização das normas, essas circunstâncias causaram maior sofrimento para as pessoas que moravam na área mais vulnerável do Haiti. Com a destruição de suas moradias pela tragédia, milhares de pessoas deixaram suas casas e invadiram terras vazias, as praças públicas e também criando problemas com os proprietários privados do terreno.

Na situação atual, é impossível que o Estado tenha um plano diretor para construção na área metropolitana, pois ainda não existe um registro cartográfico atualizado para compreender com precisão a quantidade de pessoas que se estabeleceram em cada área ocupada, nem se sabe exatamente o que de fato precisa ser melhorado em uma ação de planejamento de construção urbanística. Com os projetos financiados pelos doadores estão vinculados geralmente aos bairros, não estão ligados a nenhuma divisão administrativa da cidade.

No contexto da organização socioespacial atual, a percepção da urbanização não é uma questão de transformar a estrutura urbana, mas isso se relaciona mais à questão social e política desta cidade, e também pode ser determinado pela função de desenvolvimento da sociedade. Sendo assim, a urbanização e a cidade são as formas de aprendizagem das políticas. De fato, com o estabelecimento da cidade, os cidadãos podem aprender a lidar, viver e entender novas normas e princípios, que fazem com que a convivência das pessoas na cidade se torne a primeira escola de aprendizagem, de socialização e de política (Clos, 2014). Segundo o autor, a política da urbanização como uma moeda que possui dois lados: no primeiro lado, usa-se a urbanização como vontade política, também vista como uma 
criação humana. E, no segundo lado, tem-se a urbanização como uma ciência, que, de acordo com o autor, não pode ser improvisada, na medida em que existem normas técnicas para o entendimento dos processos. Porém, essas normas ou princípios são diferentes e inconcebíveis para a compreensão da política da urbanização desta cidade (ibidem, 2014).

Desse modo, a urbanização desequilibrada que está se posicionando ao longo da seção sudoeste do eixo principal da cidade de Porto Príncipe permite um congestionamento da saída da via principal para o sul do país e faz com que haja uma ruptura no funcionamento da população que mora na capital do país. Nesse caso, essas limitações se reorientam não só na dinâmica industrial, mas afetam também as áreas residenciais que se situam nas partes norte e nordeste de Porto Príncipe. Sendo assim, a construção de estradas na parte norte e ao sudeste, onde há maior acumulação da população, cria uma nova classe ou divisão econômica e social na área portuária de Porto Príncipe, acarretando um benefício muito grande para a indústria moderna do país. Ademais, pode permitir que a minoria da população mais rica do país se torne os principais beneficiários para construir novas indústrias na parte norte da cidade, onde se verifica uma maior concentração populacional (Godard, 1988).

Apesar do fato mencionado acima, em 2010, o Ministério da Economia e das Finanças relatou que o desafio da economia do Haiti apresenta-se na incapacidade de os sistemas urbanos conseguirem assegurar a ascensão da economia, na medida em que as áreas urbanas dos municípios não apresentam capacidades econômicas melhores do que as áreas rurais. Além disso, a primeira lógica de ação permite observar que a característica da dinâmica territorial é a ultra metropolitana da cidade de Porto Príncipe enquanto a segunda lógica é que as aglomerações urbanas municipais enfrentam uma situação de crise que pode ser representada pela seguinte forma: tanto de um processo de construção de favelas na cidade de Porto Príncipe quanto um forte movimento urbano que afeta todos os estratos sociais (Duval, 2013).

Ainda assim, a maioria dos empreendimentos habitacionais é realizada na cidade de Porto Príncipe por promoção individual. No entanto, eles não são realizados isoladamente e raramente são concluídos de uma só vez, porque dependem da capacidade financeira dos construtores. Também existe na grande periferia, como dentro do tecido urbano, operações 
de grupo realizadas por iniciativa das autoridades ou no âmbito da cooperação e operações realizadas por ONGs que trabalham na construção de moradias.

A proporção de novos habitantes nesses bairros é muito alta: em média $27 \%$ dos domicílios pesquisados na ravina de Bois de Chêne e 35\% daqueles que estavam nas "novas periferias", chegaram depois de 2010, a proporção pode subir muito mais em áreas como Coral-Canaan, quase desabitada antes do terremoto.

Segundo à hipótese do Milton Santos (1979), para que exista uma cidade, de um lado, deve haver urgência que exijam ser satisfeitas constantemente, porém é necessário, e por outro lado, que existiam atividades regulares particularmente destinadas a atribuir a essas necessidades. Apoia-se nesta reflexão de Milton Santos com relação ao que deve ser uma cidade, dizendo que é essencial que haja atividades, as quais devem responder às necessidades da população local, e que, no que lhe diz respeito, diversificam em função da densidade demográfica, da economia da região e das comunicações, bem como do comportamento socioeconômico de seus habitantes (Santos, 2004).

É importante ressaltar que o tecido urbano da cidade de Porto Príncipe é composto por dois terços de bairros não planejados, não obrigatoriamente bidonvilles, mas de disposição anárquica. No entanto, a complexidade da organização espacial da cidade de Porto Príncipe reside na falta de controle da urbanização que conheceu o país, mesmo antes do desastre de 2010 (Theodat, 2013; Desrosiers, 2017).

Na perspectiva de aglomeração populacional ao redor da cidade, segundo Aristide (2014), essa forma de urbanização ocasiona um desequilíbrio socioeconômico na organização do espaço e nas ações políticas. Para as zonas de aglomeração com habitantes que vivem abaixo da linha da pobreza, há grandes desigualdades sociais, além de deficiências nas infraestruturas e nos serviços sociais básicos. Portanto, na análise do Santos (2004), as implicações da favela no espaço urbano, sobretudo no aspecto econômico, apresentam características internas diferentes. Assim, essas favelas e cortiços instalam-se nos países subdesenvolvidos e apresentam uma existência variável.

Nestes processos de crescimento da urbanização, duas características principais parecem atuar na direção de um reforço das vulnerabilidades por efeito da exposição: os locais de apoio dessa expansão e a qualidade do tecido urbano produzido (Corrêa, 1989). Com base 
desta análise, podemos ressaltar que instalação em locais perigosos é um fenômeno abundantemente encontrado em nossas duas áreas de estudo. Isso é explicado, por um lado, pela forte pressão de urbanização que afeta todos ou parte desses setores, devido à sua localização vantajosa, particularmente a proximidade de um eixo principal que conecta o coração urbano de Port-au-Prince ou Pétion-Ville, ou seja, as áreas de emprego e serviços. A instalação é feita em detrimento da segurança. Além disso, uma parte significativa do novo edifício está em moradias precárias, embora varie de acordo com o setor (Milian e Tamru, 2018). Nesse aspecto, a dinâmica de espalhamento e densificação assume o padrão de diferenciação e segregação socioespacial, marcada por fortes tensões de terra. Os mais pobres geralmente não têm escolha a não ser se instalar em terras menos procuradas, longe do centro, localizadas em encostas íngremes.

Levando-se em consideração os aspectos mencionados, com presença ou ausência em maior ou menor grau, acarretaria à segregação socioespacial resultando na divisão do espaço urbano entre a cidade formal, dos integrados (os incluídos) e a cidade informal, dos não-integrados (os excluídos), evidenciando a forma desigual com que o espaço é apropriado pelas classes sociais, em especial nas metrópoles e cidades grandes (Maricato, 2003; Liberato, 2009), como é referido no caso da cidade de Porto Príncipe.

Portanto, essa cidade e espaço urbano se localizam e se submergem no cotidiano, por isso possui uma função fragmentada dentro de uma produção urbana. Tudo isso é pautado pela subsistência social dessa população através da morada e do trabalho, parte da estrutura do prédio edificado pelas classes dominantes. Todavia, o cotidiano que se põe na área urbana se representa como a materialização da organização social da classe inferior, negligenciada e segregada em relação à construção das cidades e dos espaços urbanos. Portanto, observase que a cidade de Porto Príncipe, com o resto de sua área metropolitana, compreende a maior concentração urbana do Haiti. Assim como as outras grandes áreas urbanas mundiais, sofre atualmente com problemas de excessos na rigidez de seus meios de circulação, com o movimento das pessoas, com crises habitacionais e com dificuldades em impulsionar a sua economia, especialmente depois do terremoto de 2010. 


\section{Novas perspectivas para as mudanças socioeconômicas da cidade em questão}

Logo depois o terremoto de 2010, o Estado deveria ter tomado uma nova medida para a reestruturação de um sistema de planejamento a fim de que o Haiti tivesse uma nova possibilidade de mudança socioeconômica. Ademais, era necessário também de elaborar novo plano de reconstrução da cidade. Sendo assim, após esse período de reestruturação, o Estado precisa colocar em prática as normas e métodos que permitam às pessoas moradoras das margens dos rios e com casas danificadas aplicar aquilo que foi estabelecido, minimizando os riscos de desastres para esta parcela da população. Em virtude da tragédia, grande parte das pessoas deixou a área metropolitana de Porto Príncipe em direção a suas cidades de origem.

Nesse contexto, o Estado deve aproveitar tal possibilidade para criar mecanismos de investimento referentes aos problemas centrais dessa área, como habitação, educação, saúde e transporte coletivo. De tal modo, poderá superar essa desorganização social, um dos pontos culminantes na criação de transtornos diários no meio da sociedade haitiana, por falta de um novo projeto ou planejamento urbano, algo indispensável para o crescimento da economia, com a participação e integração da sociedade no processo da reconstrução do país.

Cano (2011) defende que o Estado deve pensar num plano de descentralização e de desconcentração de empresas, de serviços, de produção, ou de recursos públicos, como um procedimento através do qual uma quantidade de bens, materiais ou imateriais, passariam a transitar fisicamente de uma localidade para outra por meio da rede estabelecida para facilitar a circulação do mercado regional, local e nacional. O Estado pode desenvolver uma política urbana para fazer crescer a produção nacional no intuito de responder as necessidades básicas da população nacional, e essa política aplicada permite que a economia nacional se volte para dentro, por meio de circulação interna da mercadoria. Por isso, o Estado deve pensar num plano global e nacional para dinamizar a economia urbana de maneira específica com o objetivo de transcender os limites urbanos através de uma dinâmica social, política e econômica. 
Na compreensão de Schmidt (1983), pode ser afirmado que, na política urbana ao nível de circulação, o Estado deve impulsionar condições que exigem a construção de redes de comunicação mais rápidas, redes que proporcionam a ampliação de unidades produtivas cujas vantagens sejam monopolísticas. Com isso devemos compreender a política para incentivar a instalação de projetos de conglomerados, reduzindo os custos de transportes e de meio de comunicação, posteriormente mencionados pelo Estado como meio para colocar em evidência o processo de desenvolvimento através da criação de empregos suplementares. Porém, a política da urbanização da cidade passa a ser alvo político, com objetos políticos, tendo como principal foco a organização e a satisfação das demandas públicas, além de responder as demandas sociais da natureza urbana.

Baseando-se nessa análise, Santos (2002) argumenta que, com o processo de globalização da produção, a articulação predomina sobre a produção. Assim, os fluxos possuem uma grande relevância para o esclarecimento de uma determinada situação da cidade. Entretanto, o próprio modelo geográfico determinado pela circulação, mais extensa, densa, e mais numerosa, mantém o comando da transformação de valor do espaço.

Nessa perspectiva, é necessário ter planos estratégicos para o desenvolvimento urbano poder usar como uma base para consulta aos atores locais, regionais e nacionais fundados nos acordos necessários para uma ocupação local e nacional, com a preocupação de dar uma resposta mais rápida às necessidades e na mobilização dos conhecimentos nacionais e internacionais concedidos. De fato, a execução e a formulação, dos planos de gestão estratégica e do crescimento urbano podem cooperar para o fortalecimento das políticas de descentralização dos órgãos centralizados. Cabe ressaltar, ainda, que os modelos de planos estratégicos de desenvolvimento urbano são necessários para promover as cidades e favorecem o desenvolvimento econômico local, regional e nacional sustentáveis e socialmente inclusivos na cidade (MPCE, 2010). Contudo não poderia ficar de fora uma participação da sociedade, como atores locais e regionais nesses planos estratégicos, a fim de que os anseios da população sejam considerados e debatidos na concepção das possíveis medidas de atuação do Estado, de uma maneira que as vozes da população sejam ouvidas. Portanto, propor medidas sem a participação popular implicaria uma imposição dos interesses dos governantes e das classes dominantes do país. 
Desse modo, Schmidt (1983) enfatiza que a política urbana deve ser relacionada à evolução determinada pela necessidade de uma totalidade social. Neste contexto, a intervenção do Estado no meio urbano, que é um dos instrumentos complexos destinados a remover os obstáculos, reais ou possíveis, completa a socialização do espaço urbano, atuando como uma ferramenta de controle político capaz de gerar aumentos de poder para as classes dominantes. A política urbana, como uma política específica, é, assim, um meio de integrar ambas as dimensões, a economia e a política, de uma forma social histórica.

Segundo Cano (2011), o Estado deveria colocar em prática uma fórmula simples de descentralização nos municípios para atrair as indústrias nos diferentes setores do país. Assim, ao repensar as readequações das regiões metropolitanas, também prepararia uma nova perspectiva de adequação das áreas de menores dimensões em outras cidades, a fim de antecipar o agravamento dos problemas que insistirão nas grandes áreas metropolitanas de um país e que vêm produzindo a destruição das cidades de dimensão média e grande. Além disso, a região metropolitana pode estar inserida em uma nova postura política e poderia passar por um processo de revitalização das questões de finanças públicas, favorecendo a reconstrução das linhas mais gerais de uma dinâmica e efetiva política de localização das atividades econômicas do país. Neste contexto, o processo de adequações das regiões metropolitanas deve ser visto com outro olhar na gestão das finanças e dos gastos públicos, buscando-se, também, elaborar um plano urbano que seja capaz de cumprir os principais interesses da sociedade, e não somente aqueles referentes aos determinantes dos proveitos imobiliários, que também podem participar no processo de viabilização para resolução dos problemas urbanos.

Na análise de Rochefort (1998), a estrutura apresentada nas atividades coletivas poderia ser estabelecida para cada acumulação de pessoas que consiga responder às necessidades básicas da sociedade situada na área urbana e nas periferias, reconhecendo que essas atividades apresentam uma estrutura que pertence exclusivamente a cada categoria funcional nas cidades metropolitanas. Neste contexto, o mercado imobiliário se torna um grande responsável por esse desnível socioespacial, na medida em que a escassez de recursos urbanos provoca uma procura excessiva por áreas que o possuem, acarretando uma valorização diferencial do espaço, que é leiloado pelo mercado imobiliário. 
A única medida tomada como precaução, é assegurar que as pessoas ou populações residentes trabalhem realmente na cidade e não se desloquem cotidianamente para garantir as atividades em outra aglomeração. Com isso, a noção de rede urbana regional acarreta uma ferramenta essencial na constituição de base tanto na formação geografia das cidades quanto na geografia regional para a demarcação da área metropolitana devido à concentração das atividades econômicas. Ao possuir unidade na dinâmica econômica da estrutura da geografia urbana, torna-se a rede regional na qual era essencial relocalizar cada cidade para interpretá-la de maneira concreta. Em razão disso, esta rede deve estabelecer a estrutura para um novo recorte regional para a área metropolitana.

Na proposta de Santos (2002), a realidade das redes estabelecidas nas grandes cidades, tem de ser vista como o produto da condição contemporânea das técnicas. Assim, para fazer funcionar as redes da cidade, formada através da verticalização dos fluxos de pontos, acarretando elemento regulador nas diferentes escalas geográficas, cabe renovar e recriar as horizontalidades do espaço da contiguidade. A partir dessa série de relação, deve-se perceber que a racionalidade faz-se surgir das condições do mundo contemporâneo, além de ansiar a difusão da racionalização de hegemonia nos vários aspectos da vida social, econômica, política, cultural, que conduz à instalação da racionalidade da própria construção do território.

Assim, uma nova perspectiva de mudança socioeconômica na área metropolitana de Porto Príncipe tem como desafio atender a tudo que foi mencionado acima. Como percebido, tal tarefa não é das mais fáceis, como ocorre em qualquer grande área metropolitana mundial. E o desafio haitiano ainda torna-se mais complexo ao observamos o cenário atual do país cuja própria soberania é limitada constantemente pelas grandes potências mundiais, que direcionam para onde cada financiamento tem de ser destinado, impedindo o Haiti de governar a si próprio - para saber mais sobre a discussão da soberania do Estado haitiano, consultar os trabalhos de Thizy (2003): "Haiti où la souveraineté est impossible" e Sainté (2017): “Uso do território e o papel da Organização das Nações Unidas (ONU) na ajuda humanitária no Haiti de 2010 a 2012". 


\section{Considerações finais}

Este trabalho discutiu algumas abordagens sobre a política da urbanização do Estado e a nova perspectiva para o desenvolvimento socioeconômico da cidade de Porto Príncipe (Haiti). A região metropolitana de Porto Príncipe enfrentou recentemente um período conturbado em sua história, tal como o resto do país, ao ter sido abalada por sucessivos desastres naturais e sociopolíticos, desde o terremoto de 2010, passando por tempestades e até uma ocupação militar de seu território, que ainda está em vigor. Dada essa questão, é possível que o Estado reveja o seu projeto de planejamento urbano sob uma nova perspectiva de futuro, como uma oportunidade de uma maior inclusão e integração da sociedade haitiana na participação de tais projetos como um dos atores regionais e nacionais na sua criação.

Para a realização dessa tarefa, o Estado deveria investir na criação de redes que permitam a circulação mais eficiente de mercadorias e fluxos, de modo que essa circulação de bens materiais e imateriais possa ser alcançada por todos os indivíduos do país, não se concentrando em um único ponto central. Nesse sentido, é de suma importância que haja uma descentralização dos serviços oferecidos, bem como o descongestionamento das grandes empresas e indústrias e dos serviços públicos sensíveis para que a população das áreas mais afastadas ou das periferias consiga ter acesso não somente às necessidades e aos serviços básicos.

De tal maneira, com essa nova política de desconcentração urbana, a sociedade de tais áreas mais distantes do centro urbano principal do país teria a possibilidade de não deixar a sua cidade em busca de serviços na área metropolitana. Com essa descentralização, as sociedades dessas áreas conseguiriam ter acesso também a uma maior oferta de emprego e de desenvolvimento local. Sem dúvida, é necessário que toda uma série de infraestrutura seja desenvolvida para que dê suporte logístico nesse processo de revigorização dos locais menos atendidos historicamente pelas administrações anteriores no Haiti, de modo a permitir que cada departamento possa ter uma maior autonomia e poder de decisão sobre o que fazer com o seu próprio capital. 


\section{Referências}

ARISTIDE, Sibert. La question des Services sociaux dans le processus d'urbanisation accélérée de la commune de Ouanaminthe. Port-au-Prince: UEH, 2014. Trabalho de conclusão de curso

BECKER, Bertha K..A crise do Estado e a região: a estratégia da descentralização em questão.In: BECKER, Bertha K. (Org). Ordenação do território: uma questão política? Exemplos da América Latina. Rio de Janeiro: UFRJ, 1984, p. 1-36.

CANO, Wilson. Ensaios sobre a crise urbana do Brasil. 1a ed. Campinas: Unicamp. 2011. ISBN 978-85-268-09581

CLOS, Joan. Conversation avec Joan Clos. Les cahiers d'urbanisme du ciat, Secrétariat Technique du Comité Interministériel d'Aménagement du Territoire. Novembre 2014, no 1, p. 5-27.

CORRÊA, Roberto L. Interações Espaciais. In: CASTRO, Iná Elias de; GOMES, Paulo César da Costa; CORRÊA, Roberto Lobato. Explorações Geográficas. Rio de Janeiro: Betrand Brasil, 1997. p. 279-318.

CORRÊA, Roberto L. O espaço urbano. São Paulo: Ática. 1989. ISBN 85-08-03260-9

DESROSIERS, Ismane. Haiti: um olhar crítico sobre o processo de urbanização de Canaan após 2010. Revista, Boletim Campineiro de Geografia, 2017, vol. 7, o 2, p.383-404.

DUVAL, Carline J. Coissance des villes en taille e en nombre: Causes et consequences. In: XXVII è congrès internacional de la population organise par l'Union Internationale pour l'etude Scientifique de la population (UIESP). Basan, Coreia do Sul, 2013 [Consult. 24 Out. de 2019]. Disponível em: file:///C:/Users/Guerby/Downloads/CROISSANCEDESVILLESENTAILLEETENNOMBRECarlineJOSEPHDUVAL.pdf.

EMMANUEL, Evens; THERMIL, Kareen; PHILIPPE Auguste, et al. Analyse de la situation de l'habitat en haiti. In: centre d'habitat salubre de la république d'haïti; et: En collaboration avec l'organisation panaméricaine de la santé organisation mondiale de la santé. Port-au-Prince: UNIVERSITÉ QUISQUEYA, 2000 p.1-40. Disponível em: http://www.bvsde.ops-oms.org/bvsasv/e/diagnostico/Haiti.pdf.. Acessado em 23 de Outubro de 2019.

FORUM URBAIN NATIONAL: Construire la ville. $1^{0}$ fórum urbain national. Port-au-Prince: CIAT, Março 2014, no 1, p.1-25.

GOMES, Marcos A. S. A produção e a valorização desigual do espaço urbano em Campos dos Goytacazes-RJ: uma análise das ações do Estado e dos promotores/incorporadores imobiliários. Revista Geografares, v. 1, p. 28-41, 2015.

GUIMARÃES, Leandro S. O Modelo de Urbanização Brasileiro: Notas Gerais. GeoTextos, vol. 12, n. 1, p. 13-35, 2016.

IHSI. Intitut Haitien de Statistiqueset d'fnormatique. Population totale de 18 ans et plus: menages et dansité estimés em 2015. Direction des statistiques démographiques et sociales (DSDS), 2015. Disponível em: http://www.ihsi.ht/pdf/projection/Estimat_PopTotal_18ans_Menag2015.pdf. Acessado em 24 de out de 2019.

KEANE, Bill. Haiti-past, present and future? In: Information paper prepared for the RICS Presidents desaster management commission. London: Clarkebond, Engineering and Management Consultants, Febraury 2013, p. 1-133.

Disponível

em: https://www.clarkebond.com/client/assets/media/pdfs/Haiti_Report_Past_Present_Future.pdf. Consulta: 22 de outubro de 2019.

LEFEBVRE, Henri. A Revolução Urbana. $1^{\text {a }}$ ed.. Belo Horizonte: UFMG, 2004. ISBN 978-8570411952

LEFEBVRE, Henri. O direito à cidade. 5ạ ed ..São Paulo: Moraes, 1991b. [1968]. ISBN 978-85-88208-97-1-1

LIBERATO, Rita de Cássia. Cidade e exclusão: o lugar de moradia dos excluídos: o caso de Belo Horizonte. Minas: PUC, 2009. Tese de Doutorado

LOMBART, Marie; PIERRAT, Kevin; REDON, Marie. Port-au-Prince: un projectorat haïtien ou l'urbanisme de projets humanitaires en question. Cahiers des Amériques Latines, setembre 2014, vol. 75, p. 96-123. 
MARICATO, Ermínia. Urbanização Brasileira e Redescobertas. 1ạ ed..Belo Horizonte: C/Arte, 2003. ISBN 9788587073624

MILIAN Johan; TAMRU, Bezunesh. Port-au-Prince, ville du risque ? Un mythe au prisme d'une urbanisation vulnérable. Revista Études Caribéennes, 2018, vol.39, n 40, p.1-19.

MORAES, Antonio Carlos Robert. Território e história no Brasil. 2o ed.. São Paulo: Annablume, 2005. ISBN 9788539102167

MPCE. Planification stratégique de la région métropolitaine de Port-au-Prince. Port-au-Prince: résultats de I'atelier de lancement, 2010, $\mathrm{n}^{\circ} 1$, p. 29-31.

ONU. HABITAT. World Cities Report 2016: Urbanization and development: emerging futures. Kenya: Nairobi, 2016. ISBN 978-92-1-132708-3

ROCHEFORT, Michel. Redes e sistemas: ensinando sobre o urbano e a região. 1 a ed.. São Paulo: Hucitec, 1998. ISBN 9788527104289

SAINTE, G. Uso do território e o papel da Organização das Nações Unidas (ONU) na ajuda humanitária no Haiti de 2010 a 2012: MINUSTAH (Missão de Estabilização de Paz ao Haiti). Trabalho de Conclusão de Curso, Instituto de Geociências, Unicamp. Campinas, 2017. 132p.

SANTOS, Boaventura de Souza. O Estado, o Direito e a Questão Urbana. Revista Crítica de Ciências Sociais, $1982, n^{\circ}$ 9, p.9-86.

SANTOS, M; SOUZA, Maria Adélia A.; SILVEIRA, Maria L. Território: globalização e fragmentação. 3ạ ed.. São Paulo: Hucitec, 1996. ISBN 978-8527102735

SANTOS, Milton. A natureza do espaço: Técnica, Razão e Emoção. 3a ed., São Paulo: Edusp, 2002. ISBN 9788531407130

SANTOS, Milton. A Urbanização Brasileira. 5a ed.. São Paulo: Hucitec, 1993. ISBN 9788531408601

SANTOS, Milton. O Espaço dividido: os dois circuitos da economia urbana dos países subdesenvolvidos. 2aㅡ. ed.. São Paulo: Edusp, 2004. ISBN 978-85-3140833-5

SANTOS, Milton.. Espaço e sociedade: ensaios. 1o ed., Petrópolis: Vozes, 1979. ISBN 85-314-0657-9

SCHMIDT, Benicio V. O Estado e a política urbana do Brasil. Porto Alegre: UFRGS, 1983. ISBN 9788570250612

SOJA, Edward. Geografias Pós-Modernas: a reafirmação do espaço na teoria social crítica. Rio de Janeiro: Jorge Zahar, 1993. ISBN 978-8571102590

SOUZA, Charles B. G. A contribuição de Henri Lefebvre para reflexão do espaço urbano da Amazônia. Revista Confins, março 2009, $n^{\circ}$ 5, p.5-14.

THÉODAT, J, M. Port-au-Prince en sept lieux. Haïti, Sichuan, Fukushima, Etats d'urgence. Revue Outre-Terre, 2013, n³5-36, p. 123-135.

THIZY, Delphine. Haiti ou la souveraineté est impossible. Memoire de fin d'etudes, Institut d' études politiques de Lyon, Universitè Lumière Lyon 2. Lyon, 2003. 127p. 